\title{
ATITUDE EMPREENDEDORA DE PROPRIETÁRIOS E FUNCIONÁRIOS INTRAEMPREENDEDORES: UM ESTUDO COMPARATIVO ENTRE VISIONÁRIOS E VISIONISTAS
}

\author{
Wender Rodrigues de Siqueira - Universidade Federal de Uberlândia ${ }^{1}$ \\ Patricia Peghini - Universidade Federal de Uberlândia ${ }^{2}$ \\ Lionardo Dias de Souza - Universidade Federal de Uberlândia ${ }^{3}$ \\ João Bento de Oliveira Filho - Universidade Federal de Uberlândia ${ }^{4}$
}

Resumo: O empreendedorismo pode gerar riqueza para os indivíduos e agregar valor para a sociedade por meio da geração de ideias e suas implementações, proporcionando, dessa forma, inovações contínuas. O objetivo geral desta pesquisa é identificar e comparar a atitude empreendedora de proprietários versus funcionários intraempreendedores de micro e pequenas empresas do ramo de confecção, especificamente, de moda íntima. As empresas escolhidas possuem em comum o fato de todas serem micro ou pequenas e representarem uma concentração de empreendimentos deste tipo na região sudeste de Goiás. Pretendeu-se descobrir se há diferença na atitude empreendedora de proprietários (visionários) e funcionários intraempreendedores (visionistas). A abordagem utilizada foi quantitativa, conforme Carrieri e Luz (1998), com a adoção do Instrumento de Medida de Atitude Empreendedora (IMAE), proposto por Lopez Jr. e Souza (2005). A pesquisa foi realizada com indivíduos, entre empreendedores e intraempreendedores, das empresas desse ramo de atividade na cidade de Catalão, região sudeste de Goiás. Os dados foram coletados por meio de questionário, totalizando-se 30 respondidos, e consistindo-se em uma amostra por conveniência. Os resultados demonstraram não haver diferença de atitude empreendedora, especificamente para este objeto de pesquisa, entre visionários e visionistas, dentro das dimensões estudadas. Consequentemente, não se pode afirmar que existe diferença de atitude empreendedora entre proprietários e funcionários intraempreendedores nas empresas analisadas.

Palavras-chave: Atitude empreendedora, empreendedorismo, visionários, visionistas, micro e pequenas empresas.

\section{ENTREPRENEURIAL ATTITUDE OF OWNERS AND EMPLOYEES INTRAPRENEURS: A COMPARATIVE STUDY OF VISIONARY AND VISIONISTAS}

Abstract: Entrepreneurship can generate wealth for individuals and add value to society through the generation of ideas and their implementations, providing thus

\footnotetext{
${ }^{1}$ E.mail: wendersiqueira@gmail.com- Endereço: Av. João Naves de Ávila, 2121 - Santa Mônica, Uberlândia - MG, CEP: 38408-100.

${ }^{2}$ E.mail: patricia_pghn@hotmail.com

${ }^{3}$ E.mail: lionardo@pmqm.com.br

${ }^{4}$ E.mail: oliveirajoao17@gmail.com
}

SIQUEIRA, W. R.; PEGHINI, P.; SOUZA, L. D.; OLIVEIRA FILHO, J. B. Atitude empreendedora de proprietários e funcionários intraempreendedores: um estudo comparativo entre visionários e visionistas. Revista de Empreendedorismo e Gestão de Pequenas Empresas, v. 3, n.1, p. 84-104, 2014. 
continuous innovations. The objective of this research is to identify and compare the entrepreneurial attitude of owners versus employees intrapreneurs micro and small companies in the manufacturing, specifically intimate fashion. The companies chosen have in common the fact that all are micro or small and represent a concentration of enterprises of this kind in the region southeast of Goiás was intended to find out whether there are differences in entrepreneurial attitude of owners (visionary) and employees intrapreneurs (visionistas). The approach used was quantitative, as Carrieri and Luz (1998), with the adoption of the Instrument for Measuring Entrepreneurial Attitude (IMAE), proposed by Lopez Jr. and Souza (2005). The research was conducted with individuals, between entrepreneurs and intrapreneurs, companies in this line of business in the city of Catalão, southeastern Goiás Data were collected through a questionnaire, totaling up 30 responded, and consisting in a sample for convenience. The results showed no difference in entrepreneurial attitude, specifically for this research subject, among visionaries and visionistas within the dimensions studied. Consequently, one can not say that there is a difference in attitude entrepreneurial between owners and employees intrapreneurs in the analyzed companies.

Keywords: Entrepreneurial attitude, entrepreneurial, visionary, visionistas, micro and small enterprises.

\section{Introdução}

No cenário atual, as rápidas transformações e a globalização das economias têm desafiado os empresários a incrementarem, cada vez mais, a produtividade e a competitividade dentro de suas empresas. O desafio do momento não é apenas criar uma empresa, mas, sim, torná-la sustentável, no entanto, isso demanda mais do que técnicas e infraestrutura, levando a maneiras de pensar e agir comprometidas com a inovação.

Em tempos atrás, os conhecimentos empíricos adquiridos eram suficientes para manter as empresas no mercado, porém, atualmente, conforme Souza (2006), considerando que o principal ativo das empresas são as pessoas, a atividade empreendedora demanda competências e atitudes diferenciadas dos atores nela envolvidos. Há, portanto, um crescimento no interesse de práticas empreendedoras, proporcionando desenvolvimento de pesquisas e estudos sobre empreendedorismo (BERNARDES; MARTINELLI, 2003).

Devido à globalização, diversas empresas têm buscado diferentes alternativas a fim de se adaptarem à nova realidade econômica. Nesse sentido, a

SIQUEIRA, W. R.; PEGHINI, P.; SOUZA, L. D.; OLIVEIRA FILHO, J. B. Atitude empreendedora de proprietários e funcionários intraempreendedores: um estudo comparativo entre visionários e visionistas. Revista de Empreendedorismo e Gestão de

Pequenas Empresas, v. 3, n.1, p. 84-104, 2014. 
competitividade entre as mesmas aumentou o que fez com que aumentasse a produtividade de seus processos de fabricação.

Diante das dificuldades enfrentadas pelas empresas para sobreviverem a esse mercado altamente competitivo, constata-se a importância em levantar algumas questões relacionadas às atitudes empreendedoras frente ao desafio da sustentabilidade do negócio.

Para este estudo, decidiu-se realizar a pesquisa no contexto da indústria de confecções, mais especificamente junto aos proprietários e funcionários intraempreendedores de confecções de roupa íntima. As empresas escolhidas possuem em comum o fato de serem todas micro e pequenas, e representarem uma concentração de empreendimentos deste tipo. Elas são tidas como fonte de oportunidades para a criação de um número crescente de novos negócios, mas vivenciam dificuldades relacionadas à manutenção e sobrevivência, e são constantemente obrigadas a inovarem para se manterem no mercado. Porém, nem sempre há condições suficientes para fazê-lo, pois, além de faltarem recursos financeiros e preparo de seu criador, muitas vezes, experimentam uma concorrência desleal por parte das grandes empresas.

No contexto do setor têxtil, destaca-se a concorrência chinesa frente aos produtos nacionais, com o crescente volume de artigos de confecções importados deste país, de acordo com levantamento da Associação Brasileira de Indústria Têxtil e de Confecção - ABIT. Neste aspecto, a concorrência para os empresários brasileiros ocorre em condições desiguais, uma vez que os juros, a carga tributária e o custo da mão-de-obra são muito maiores, em comparação aos praticados na China (ABIT, 2011).

Além disso, o desempenho chinês está ligado, principalmente, à orientação desta economia para a inovação, conforme estudo realizado pelo Instituto de Estudos para o Desenvolvimento Industrial - IEDI, no qual foi citado o investimento em P\&D da China 6,5 vezes superior ao do Brasil, em 2009. Observa-se que "o ritmo da mudança não se reflete apenas no gasto. O dinamismo cria outro ambiente, estimula o investimento privado, muda culturas e comportamentos, induz o risco, coloca a economia em contato com o mundo e premia o sucesso" (IEDI, 2011, p.3).

SIQUEIRA, W. R.; PEGHINI, P.; SOUZA, L. D.; OLIVEIRA FILHO, J. B. Atitude empreendedora de proprietários e funcionários intraempreendedores: um estudo comparativo entre visionários e visionistas. Revista de Empreendedorismo e Gestão de

Pequenas Empresas, v. 3, n.1, p. 84-104, 2014. 
Enquanto as grandes empresas utilizam, constantemente, inovações tecnológicas, seja através de uma estrutura própria de pesquisa, desenvolvimento ou da aquisição de tecnologia desenvolvida por outras empresas, as micro e pequenas empresas apresentam restrições financeiras para arcarem com os custos da inovação.

Para se sustentarem no mercado as empresas desse porte precisam buscar alternativas, e a capacitação para um comportamento inovador e empreendedor é uma delas. Nesse tipo de empresa, o empreendedor é visto como tomador de decisões relativas à inovação, assumindo, então, a responsabilidade pelos resultados. Assim, é preciso conhecer as características pessoais do indivíduo capaz de levar a companhia à sustentabilidade e ao desenvolvimento.

A partir do exposto, o objetivo geral desta pesquisa é identificar a atitude empreendedora dos proprietários e funcionários intraempreendedores de micro e pequenas empresas do ramo de confecção, especificamente de moda íntima, frente ao seu negócio. Os objetivos específicos são: compreender o conceito de empreendedorismo e sua evolução conceitual; discorrer sobre o intraempreendedor; caracterizar visionários e visionistas; identificar as principais características comportamentais e atitudes do empreendedor; e fazer um comparativo entre as atitudes empreendedoras dos proprietários (visionários) e dos funcionários intraempreendedores (visionistas).

A pretensão em desenvolver esta pesquisa é medir a atitude empreendedora, acreditando que, partindo desta análise, será possível avaliar o grau empreendedor dos proprietários e dos funcionários intraempreendedores das micro e pequenas empresas escolhidas. Há, ainda, a possibilidade de este estudo servir como suporte para o entendimento de atitude empreendedora em outras empresas de mesmo porte e ramo de atividade, bem como para futuros estudos correlatos. Afinal, segundo Filion (1991), pesquisar empreendedores bem sucedidos permite identificar as características que devem ser aperfeiçoadas para obter sucesso.

A seguir, são apresentados os aspectos metodológicos utilizados na pesquisa. Os resultados obtidos são descritos e discutidos e, por último, são 
explicitadas as considerações finais, sem a intenção de esgotar o assunto em questão.

\section{EMPREENDEDORISMO}

O empreendedorismo é um processo que se inicia com o reconhecimento de uma oportunidade e/ou uma ideia para algo novo (BARON; SHANE, 2007). Nessa perspectiva processual considerada por Baron e Shane (2007), as fases que se sucedem são: o planejamento e a reunião dos recursos iniciais, o lançamento de um novo empreendimento, a construção do sucesso e a colheita das recompensas. Assim, para Baron e Shane (2007, p. 18), "no centro do empreendedorismo há um ponto de encontro de oportunidades e pessoas. É essa conexão ou interseção que dá início ao processo".

\section{Empreendedores}

O Quadro 1 apresenta a evolução da pesquisa sobre empreendedores, iniciada pelos franceses Richard Cantillon, no século XVIII, e Jean-Baptiste Say, no século XIX, à época classificados como economistas. Ambos "consideravam os empreendedores como pessoas que corriam riscos, basicamente porque investiam seu próprio dinheiro" (FILION, 1999, p. 7). Enquanto o primeiro autor abordou os empreendedores como "pessoas que aproveitam as oportunidades com a perspectiva de obterem lucros, assumindo os riscos inerentes" (FILION, 1999, p. 7), o segundo introduziu o conceito de inovação e mudança (FILION, 1999).

No início do século XX, o economista austríaco Joseph A. Schumpeter popularizou a inovação como característica fundamental do empreendedor (FILION, 1999), em concordância com Say e tendo sido corroborado pela maioria dos pesquisadores que o sucederiam. Além disso, Schumpeter se destacou pela utilização da expressão "processo de destruição criativa", que atribuiu ao empreendedor (DEGEN, 2009, p. 5):

SIQUEIRA, W. R.; PEGHINI, P.; SOUZA, L. D.; OLIVEIRA FILHO, J. B. Atitude empreendedora de proprietários e funcionários intraempreendedores: um estudo comparativo entre visionários e visionistas. Revista de Empreendedorismo e Gestão de

Pequenas Empresas, v. 3, n.1, p. 84-104, 2014. 
Esse processo [de destruição criativa] é o impulso fundamental que aciona e mantém em marcha o motor capitalista. É por meio dele que são gerados, constantemente, novos produtos, serviços, métodos de produção e mercados. Ele destrói sem cessar os produtos e serviços estabelecidos no mercado, substituindo-os por novos, mais eficientes e baratos. Ele subverte sem trégua a estrutura econômica existente, criando, sem parar, uma nova, mais forte do que a anterior.

Quadro 1 - Evolução da pesquisa sobre empreendedores

\begin{tabular}{|c|c|c|c|}
\hline ESCOLAS & AUTORES & PERÍODOS & $\begin{array}{l}\text { CARACTERÍSTICAS DOS } \\
\text { EMPREENDEDORES }\end{array}$ \\
\hline \multirow{3}{*}{ Econômica } & Richard Cantillon & Século XVIII & $\begin{array}{l}\text { Aproveitamento de } \\
\text { oportunidades e perspectiva de } \\
\text { lucros mediante riscos (FILION, } \\
\text { 1999). }\end{array}$ \\
\hline & Jean-Baptiste Say & Século XIX & $\begin{array}{l}\text { Inovação e mudança (FILION, } \\
\text { 1999). }\end{array}$ \\
\hline & $\begin{array}{l}\text { Joseph A. } \\
\text { Schumpeter }\end{array}$ & Início do séc. $X X$ & $\begin{array}{l}\text { Inovação e destruição criativa } \\
\text { (DEGEN, 2009). }\end{array}$ \\
\hline \multirow{2}{*}{ Comportamentalista } & Max Weber & Início do séc. $X X$ & $\begin{array}{l}\text { Independência e liderança } \\
\text { (FILION, 1999). }\end{array}$ \\
\hline & $\begin{array}{l}\text { David C. } \\
\text { McClelland }\end{array}$ & $\begin{array}{l}\text { Meados do séc. } \\
\text { XX }\end{array}$ & $\begin{array}{l}\text { Necessidade de realizar } \\
\text { (DEGEN, 2009). }\end{array}$ \\
\hline
\end{tabular}

Fonte: Elaborada pelos autores com base em Filion (1999) e Degen (2009).

Com outro enfoque, a escola comportamentalista teve como ênfase o comportamento humano do empreendedor, pesquisado a partir do início do século XX, por autores como o sociólogo alemão Max Weber e pelo psicólogo americano David C. McClelland. Esse último indicou a "necessidade de realizar" como característica associada ao empreendedor bem sucedido, cuja vontade de vencer todas as dificuldades para desenvolver seu negócio, o desafia a pagar o preço do sacrifício pessoal para ter sucesso (DEGEN, 2009, p. 14). Os autores comportamentalistas sucessores de McClelland dominaram esse campo até o início dos anos de 1980 (FILION, 1999).

Já no final do século XX, o canadense Louis Jacques Filion contribuiu para o estudo do empreendedorismo apresentando sua teoria visionária, na qual o empreendedor imagina e desenvolve uma visão sobre aquilo que pretende realizar (FILION, 1991).

SIQUEIRA, W. R.; PEGHINI, P.; SOUZA, L. D.; OLIVEIRA FILHO, J. B. Atitude empreendedora de proprietários e funcionários intraempreendedores: um estudo comparativo entre visionários e visionistas. Revista de Empreendedorismo e Gestão de

Pequenas Empresas, v. 3, n.1, p. 84-104, 2014. 
Intraempreendedores

Para Baron e Shane (2007, p. 8), "os indivíduos que atuam como empreendedores em uma empresa são frequentemente descritos como empreendedores internos - pessoas que criam algo novo, dentro de uma empresa existente, em vez de fundar um novo negócio". De acordo com Filion (2004, p. 74), esses empreendedores internos, ou intraempreendedores, são "pessoas que desempenham um papel empreendedor dentro das organizações".

Pinchot (1989), o primeiro autor a utilizar o termo "intrapreneur", aponta a semelhança entre intraempreendedores e empreendedores, indicando que ambos assumem riscos, diferenciando os dois apenas pelo fato de o trabalho do primeiro estar voltado para dentro das organizações já estabelecidas, e não para fora delas. Segundo Dornelas (2003, p. 12), "a idéia de se atribuir o empreendedorismo apenas à criação de novos negócios é muito limitada (...) é possível trazer esse conceito para dentro das organizações estabelecidas $e$, ainda, fazer com que essas organizações tenham um diferencial com isso".

Dentro das empresas, a atuação desses agentes inovadores é geralmente precedida por planejamento e pela gestão do risco, o que possibilita o alinhamento de suas ações aos interesses organizacionais (PINCHOT, 1989). Nesse aspecto, conforme Filion (2004, p.66):

O desenvolvimento e a implementação de visões são duas das principais características das ações empreendedora e intraempreendedora. É difícil imaginar uma ação inovadora que não tenha sido precedida por uma reflexão ou interiorização que leva o autor da ação a imaginar e a visualizar as coisas segundo uma determinada orientação. Para fazer algo diferente, os inovadores têm que, primeiro, identificar o que querem fazer, visualizar isso e, então, identificar a melhor forma de transformar a inovação em realidade. Além disso, precisam ter energia e vontade para estruturar o processo em andamento.

Filion (2004, p. 74) indica "três práticas de administração para incentivar o intraempreendedorismo": (1) seleção de empregados (quanto maior a empresa, maior deve ser o recrutamento de funcionários com perfil empreendedor); (2)

SIQUEIRA, W. R.; PEGHINI, P.; SOUZA, L. D.; OLIVEIRA FILHO, J. B. Atitude empreendedora de proprietários e funcionários intraempreendedores: um estudo comparativo entre visionários e visionistas. Revista de Empreendedorismo e Gestão de

Pequenas Empresas, v. 3, n.1, p. 84-104, 2014. 
estabelecimento de contrato psicológico entre empresa e funcionário; e (3) utilização de ferramentas de intraempreendedorismo (caixa de sugestões, criação de clubes, sugestões de novos produtos por funcionários de outras áreas, entre outras ferramentas).

Pinchot (1989) considera, porém, que as empresas muitas vezes não possuem uma cultura empresarial para a identificação de ideias e conversão destas em algo viável. Dessa forma, as organizações que desejam ser intraempreendedoras devem facilitar o sistema de comunicação, saber lidar com os conflitos e resistências a mudanças, recompensar o sucesso e minimizar os erros. Além disso, devem estimular a visão sistêmica e treinamentos de funcionários, inclusive, com foco em gestão de risco, de forma a prepará-los para o processo visionário pretendido pela organização (FILION, 2004).

\title{
Visionários e Visionistas
}

Ações empreendedoras e intraempreendedoras são caracterizadas, principalmente, pelo desenvolvimento e implementação de visões (FILION, 2004). As visões podem ser classificadas em três categorias: emergentes, centrais e complementares, conforme Filion (2004). Assim, as visões emergentes darão origem a uma visão central, que dependerá das visões complementares para sua realização e evolução, conforme Figura 1. Nesse contexto:

\begin{abstract}
Através dos anos, os empreendedores desenvolverão várias visões emergentes - ou idéias de produto - até que achem a idéia (ou a visão emergente) que pode se tornar uma visão central. Uma vez estabelecida a visão central, para fazê-la acontecer, é necessária uma série de ações concretas o u de visões complementares. As visões complementares, normalmente, tomam a forma de atividades administrativas, como marketing, finanças, administração da produção, sistemas de informação, administração de recursos humanos e assim por diante [...] (FILION, 2004, p. 67).
\end{abstract}

Enquanto os empreendedores focalizam a visão central e são descritos como visionários, os intraempreendedores desenvolvem visões emergentes e complementares, sendo descritos como visionistas. Desse modo, os 
empreendedores visionários se cercarão de visionistas, sendo que esses, normalmente, possuem ideias diferentes da visão central, mas que podem contribuir com tal visão, "de modo a ampliar seu escopo e a permitir à organização realizar mais atividades em torno da visão central" (FILION, 2004, p. 70).

Figura 1 - Visão e Visões

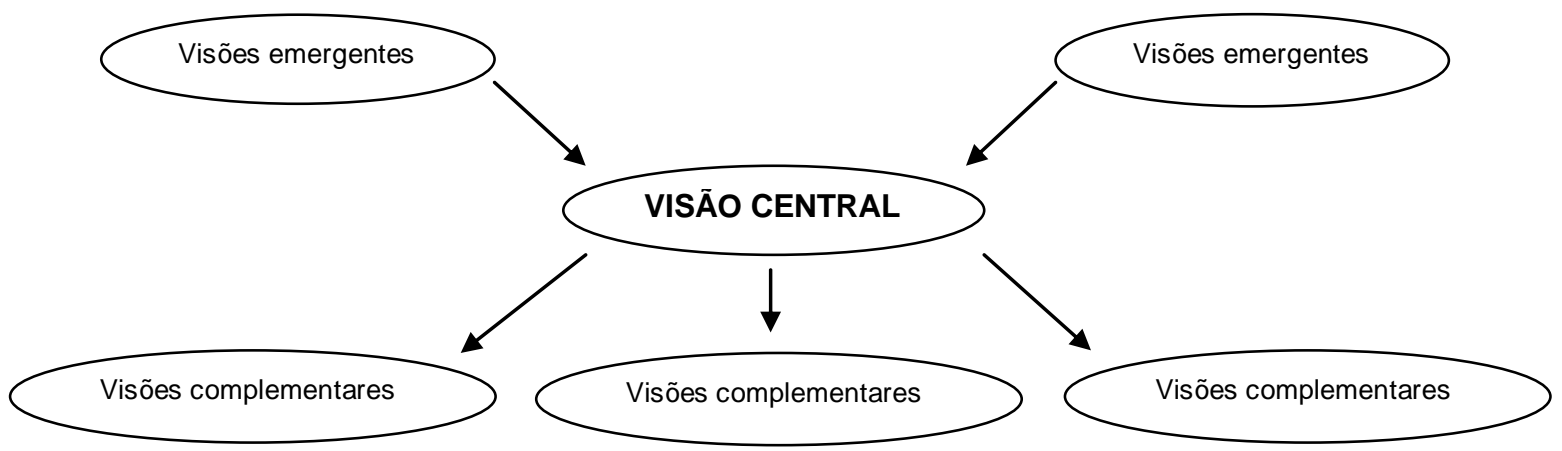

Fonte: FILION (2004, p.67)

Os visionistas são apontados por Filion (2004) como indivíduos geradores de mudanças nas organizações. Porém, tais mudanças podem trazer riscos de fracasso, os quais devem ser minimizados mediante a instituição de uma estrutura para o processo visionário, de incentivo às ações visionárias e apoio às mudanças. Para Filion (2004), os elementos que compõem esta estrutura de apoio para a ação são os seguintes: desenvolvimento de uma visão; apoio a pessoas que possuem visões; relações de apoio favoráveis ao processo de organização; cultivo de um clima visionista; iniciativas para assegurar o progresso das visões; e, avaliação do que vai sendo alcançado.

\section{CARACTERÍSTICAS COMPORTAMENTAIS E ATITUDES EMPREENDEDORAS}

O comportamento empreendedor, segundo Dornelas (2003, p. 12), "está intimamente ligado com uma orientação para a ação, pensando de forma diferente, buscando incessantemente novas oportunidades para o negócio, criando algo novo e entendendo como essas novas oportunidades poderão trazer lucros para a organização".

SIQUEIRA, W. R.; PEGHINI, P.; SOUZA, L. D.; OLIVEIRA FILHO, J. B. Atitude empreendedora de proprietários e funcionários intraempreendedores: um estudo comparativo entre visionários e visionistas. Revista de Empreendedorismo e Gestão de

Pequenas Empresas, v. 3, n.1, p. 84-104, 2014. 
Não existe, atualmente, um consenso sobre o perfil do empreendedor e suas características comportamentais, embora essa tentativa tenha sido foco de inúmeras pesquisas, conforme apontado por Filion (2000a).

Um estudo realizado pela Management Systems International - MSI (1999) identificou as características dos empreendedores bem sucedidos, agrupando-as em três principais: Planejamento, Realização e Poder, as quais foram esquematizadas no Quadro 2. O quadro traz ainda uma quarta característica, Inovação, que, apesar de não ter sido apontada pela MSI, foi encontrada em todos os trabalhos pesquisados por Souza (2006).

As quatro características, Planejamento, Inovação, Realização e Poder, promoveram embasamento para o estudo de elaboração do Instrumento de Medida de Atitude Empreendedora - IMAE, validado por Lopez Jr. e Souza (2005). Nesse estudo, convencionou-se agrupar as características comportamentais do empreendedor em duas dimensões: I - Prospecção e Inovação; e II - Gestão e Persistência, conforme Quadro 2.

\section{Quadro 2 - Características comportamentais e respectivas dimensões}

\begin{tabular}{|c|c|c|}
\hline \multicolumn{2}{|l|}{ CARACTERÍSTICAS COMPORTAMENTAIS } & DIMENSÕES \\
\hline $\begin{array}{l}\text { Estabelecimento de metas } \\
\text { Busca de informações } \\
\text { Planejamento e monitoramento }\end{array}$ & Planejamento & \multirow{2}{*}{$\begin{array}{l}\text { I- Prospecção e } \\
\text { Inovação }\end{array}$} \\
\hline $\begin{array}{l}\text { Criatividade } \\
\text { Inovação }\end{array}$ & Inovação & \\
\hline $\begin{array}{l}\text { Busca de oportunidades } \\
\text { Iniciativa } \\
\text { Persistência } \\
\text { Aceitação de riscos } \\
\text { Comprometimento }\end{array}$ & Realização & \multirow{2}{*}{$\begin{array}{l}\text { Il- Gestão e } \\
\text { Persistência }\end{array}$} \\
\hline $\begin{array}{l}\text { Persuasão } \\
\text { Estabelecimento de redes de contato } \\
\text { Liderança } \\
\text { Independência } \\
\text { Autoconfiança }\end{array}$ & Poder & \\
\hline
\end{tabular}

Fonte: Elaborada pelos autores com base em Filion (1999) e Degen (2009).

A atitude empreendedora, nesse contexto, é abordada por meio da Teoria do Comportamento Planejado (Theory of Planned Behavior) de Ajzen (1985), sendo

SIQUEIRA, W. R.; PEGHINI, P.; SOUZA, L. D.; OLIVEIRA FILHO, J. B. Atitude empreendedora de proprietários e funcionários intraempreendedores: um estudo comparativo entre visionários e visionistas. Revista de Empreendedorismo e Gestão de 
definida como uma avaliação frente a um objeto de estímulo, influenciada por crenças. Ajzen e Fishbein (2000, p.1) afirmam que “(...) as atitudes das pessoas seguem, espontânea e consistentemente, de crenças acessíveis na memória e então guiam o comportamento correspondente". O acesso às crenças varia conforme a motivação, a capacidade de classificar a relevância da atitude e o contexto (AJZEN; FISHBEIN, 2000).

Assim, a atitude prediz intenções de comportamento, que, por sua vez, representam o esforço que a pessoa estará disposta a fazer, sendo que, quanto maior o envolvimento, melhor o desempenho (AJZEN, 1991). São os fatores motivacionais, representados pela intenção, e os fatores de controle comportamental, representados pela oportunidade e recursos, que determinam a concretização de um comportamento específico (AJZEN, 1991).

Diante disso, pode-se entender por atitude empreendedora, para efeitos deste estudo, a intenção de agir de acordo com as características comportamentais apresentadas no Quadro 2.

\section{ASPECTOS METODOLÓGICOS}

A partir do embasamento teórico sobre a atitude empreendedora e com subsídio no instrumento validado por Lopez Jr. e Souza (2005) para sua medição, pretende-se responder ao seguinte problema de pesquisa: Há diferença na atitude empreendedora de proprietários (empreendedores visionários) e funcionários intraempreendedores (visionistas)?

A abordagem utilizada foi quantitativa, conforme Carrieri e Luz (1998), com a adoção do Instrumento de Medida de Atitude Empreendedora - IMAE (LOPEZ JR.; SOUZA, 2005), composto por 36 questões, que utiliza a escala tipo Likert de 10 pontos, variando de "nunca" a "frequentemente".

A coleta de dados foi realizada por meio de questionário, totalizando-se 30 respondidos, e consistindo-se em uma amostra por conveniência. A amostra da pesquisa foi composta por 14 proprietários e 16 funcionários, ocupantes do cargo de gerente de micro e pequenas empresas do setor de confecções de roupa íntima,

SIQUEIRA, W. R.; PEGHINI, P.; SOUZA, L. D.; OLIVEIRA FILHO, J. B. Atitude empreendedora de proprietários e funcionários intraempreendedores: um estudo comparativo entre visionários e visionistas. Revista de Empreendedorismo e Gestão de

Pequenas Empresas, v. 3, n.1, p. 84-104, 2014. 
localizadas na cidade de Catalão, região sudeste de Goiás, onde se encontra uma concentração de empresas desse setor. $O$ corte da pesquisa foi transversal e alguns cuidados foram tomados para se garantir o sigilo das informações e a não identificação dos participantes (MARCONI; LAKATOS, 2006).

A análise quantitativa dos dados coletados foi realizada com o auxílio do software SPSS. As técnicas de análise utilizadas foram estatística descritiva e inferencial, como teste de hipótese, utilizando t-student para averiguação de diferenças de médias (HAIR JR. et al., 2009).

O nível de análise da pesquisa é o indivíduo (proprietário e funcionário intraempreendedor) no contexto da organização e a unidade de análise é a atitude empreendedora destes indivíduos. Assim, o estudo pretende discutir os resultados encontrados, tendo como base o referencial teórico.

A priori, a escolha dos gerentes para composição da amostra de intraempreendedores merece uma ressalva, pois não se pode afirmar que a condição de gerente seja suficiente para a classificação dos funcionários como empreendedores internos (FILION, 2000b). No presente estudo, portanto, a escolha desses funcionários se deu não apenas pelo seu cargo, mas pelo seu perfil intraempreendedor (propõem melhorias para a empresa, incrementam os processos de venda e exposição de produtos, sugerem novos mix de produtos, entre outros).

\section{APRESENTAÇÃO E DISCUSSÃO dOS RESULTADOS}

$\mathrm{Na}$ amostra analisada, dos 30 respondentes, 14 ocupam o cargo de proprietário, sendo considerados empreendedores, os quais a partir de agora serão chamados de visionários, e 16 ocupam o cargo de gerente, sendo considerados empreendedores internos, ou intraempreendedores, aqui chamados visionistas.

Dentre o grupo de visionários, predominam pessoas do gênero feminino, com $92,85 \%$ e com titulação em nível de $3^{\circ}$ grau completo $(35,71 \%)$. A idade média nesse grupo é de 45,3 anos.

No outro grupo, composto por visionistas, $18,75 \%$ são do gênero masculino e $81,25 \%$ do gênero feminino. Quanto ao grau de escolaridade nesse grupo, dos

SIQUEIRA, W. R.; PEGHINI, P.; SOUZA, L. D.; OLIVEIRA FILHO, J. B. Atitude empreendedora de proprietários e funcionários intraempreendedores: um estudo comparativo entre visionários e visionistas. Revista de Empreendedorismo e Gestão de

Pequenas Empresas, v. 3, n.1, p. 84-104, 2014. 
entrevistados $31,25 \%$ possuem $3^{\circ}$ grau incompleto e, o mesmo percentual $(31,25 \%)$ $3^{\circ}$ grau completo. A idade média dos visionistas é 35,26 anos.

Para a comparação entre os grupos o estudo será realizado com base nas dimensões oriundas do instrumento IMAE (LOPEZ JR.; SOUZA, 2005), que é composto da seguinte forma:

I - Prospecção e Inovação, que contempla as assertivas: $1 ; 2 ; 3 ; 4 ; 5 ; 6 ; 9 ; 11$; $12 ; 14 ; 15 ; 16 ; 19 ; 22 ; 23 ; 28 ; 29 ; 30 ; 31 ;$ e 32 , e

II - Gestão e Persistência, com as assertivas: 8; 10; 13; 17; 18; 20; 21; 24; 25; $26 ; 27 ; 33 ; 34 ; 35$ e 36.

Dessa forma, serão testadas as seguintes hipóteses:

- Hipótese Nula para $\mathrm{H} 1$ : Não há diferença entre as médias dos empreendedores visionários e visionistas na dimensão Prospecção e Inovação.

- H1: Há diferença entre as médias dos empreendedores visionários e visionistas na dimensão Prospecção e Inovação.

- Hipótese Nula para H2: Não há diferença entre as médias dos empreendedores visionários e visionistas na dimensão Gestão e Persistência.

- H2: Há diferença entre as médias dos empreendedores visionários e visionistas na dimensão Gestão e Persistência.

O coeficiente Alfa de Cronbach mede a correlação entre respostas em um questionário por meio da análise das respostas dadas pelos respondentes, apresentando uma correlação média entre as perguntas. O coeficiente a é calculado a partir da variância dos itens individuais e da variância da soma dos itens de cada avaliador de todos os itens de um questionário que utilizem a mesma escala de medição (HORA; MONTEIRO; ARICA, 2010).

Coeficiente de confiabilidade da escala do questionário (Alfa de Cronbach): 0,86 (a tabela abaixo é a saída do SPSS para este teste)

\begin{tabular}{|l|l|r|}
\hline $\begin{array}{l}\text { Cronbach's } \\
\text { Alpha }\end{array}$ & $\begin{array}{l}\text { Cronbach's Alpha Based } \\
\text { on Standardized Items }\end{array}$ & N of Items \\
\hline, 861 &, 892 & 36 \\
\hline
\end{tabular}

SIQUEIRA, W. R.; PEGHINI, P.; SOUZA, L. D.; OLIVEIRA FILHO, J. B. Atitude empreendedora de proprietários e funcionários intraempreendedores: um estudo comparativo entre visionários e visionistas. Revista de Empreendedorismo e Gestão de 
Coeficiente de confiabilidade da escala do questionário (Alfa de Cronbach) para a dimensão Prospecção e Inovação: 0,84 (a tabela abaixo é a saída do SPSS para este teste)

\begin{tabular}{|l|l|r|}
\hline $\begin{array}{l}\text { Cronbach's } \\
\text { Alpha }\end{array}$ & $\begin{array}{l}\text { Cronbach's Alpha Based } \\
\text { on Standardized Items }\end{array}$ & N of Items \\
\hline, 842 &, 866 & 20 \\
\hline
\end{tabular}

Coeficiente de confiabilidade da escala do questionário (Alfa de Cronbach) para a dimensão Gestão e Persistência: 0,72 (a tabela abaixo é a saída do SPSS para este teste)

\begin{tabular}{|r|r|r|}
\hline $\begin{array}{l}\text { Cronbach's } \\
\text { Alpha }\end{array}$ & $\begin{array}{l}\text { Cronbach's Alpha Based } \\
\text { on Standardized Items }\end{array}$ & N of Items \\
\hline, 719 &, 775 & 16 \\
\hline
\end{tabular}

Considerando todas as respostas ao questionário, o coeficiente de confiabilidade da escala (Alfa de Cronbach) é 0,86 . Para as dimensões que foram analisadas, os coeficientes são os seguintes:

- Prospecção e Inovação: 0,84

- Gestão e Persistência: 0,72

Assim, como este coeficiente varia de 0 a 1 e, quanto mais próximo de 1 , maior a correlação entre as respostas do questionário, o resultado de 0,86 é satisfatório. Da mesma forma, considerou-se satisfatório o resultado para as dimensões Prospecção e Inovação e Gestão e Persistência, sendo respectivamente $\alpha=0,84$ e $\alpha=0,72$.

Para analisar as diferenças entre os grupos visionários e visionistas quanto à sua atitude empreendedora foram somadas as escalas (HAIR JR. et al., 2009) de cada dimensão referente aos grupos, que estão evidenciados na tabela a seguir: 


\section{mase

Tabela 1 - Somatório das dimensões por Grupo de Respondentes

\begin{tabular}{|c|c|c|c|c|c|}
\hline $\begin{array}{c}\text { GRUPO DE } \\
\text { VISIONÁRIO } \\
\text { S }\end{array}$ & $\begin{array}{c}\text { DIMENSÃO } \\
\text { PROSPECÇÃ } \\
\text { O E } \\
\text { INOVAÇÃO }\end{array}$ & $\begin{array}{c}\text { DIMENSĀO } \\
\text { GESTÃO E } \\
\text { PERSISTÊNCI } \\
\text { A }\end{array}$ & $\begin{array}{c}\text { GRUPO DE } \\
\text { VISIONISTA } \\
\text { S }\end{array}$ & $\begin{array}{c}\text { DIMENSÃO } \\
\text { PROSPECÇÃ } \\
\text { O E } \\
\text { INOVAÇÃO }\end{array}$ & $\begin{array}{c}\text { DIMENSÃO } \\
\text { GESTÃO E } \\
\text { PERSISTÊNCI } \\
\text { A } \\
\end{array}$ \\
\hline 1 & 170 & 146 & 15 & 128 & 123 \\
\hline 2 & 135 & 140 & 16 & 172 & 133 \\
\hline 3 & 159 & 123 & 17 & 163 & 127 \\
\hline 4 & 122 & 140 & 18 & 178 & 138 \\
\hline 5 & 118 & 141 & 19 & 123 & 100 \\
\hline 6 & 188 & 145 & 20 & 133 & 140 \\
\hline 7 & 155 & 136 & 21 & 157 & 144 \\
\hline 8 & 151 & 144 & 22 & 169 & 140 \\
\hline 9 & 145 & 144 & 23 & 140 & 140 \\
\hline 10 & 138 & 121 & 24 & 163 & 151 \\
\hline 11 & 196 & 152 & 25 & 147 & 124 \\
\hline 12 & 147 & 134 & 26 & 126 & 110 \\
\hline 13 & 128 & 124 & 27 & 133 & 113 \\
\hline \multirow[t]{3}{*}{14} & 159 & 142 & 28 & 127 & 140 \\
\hline & & & 29 & 160 & 142 \\
\hline & & & 30 & 147 & 126 \\
\hline
\end{tabular}

Fonte: Elaborada pelos autores.

A partir deste somatório, as médias das dimensões foram calculadas conforme tabela abaixo, apontando inicialmente que o grupo visionistas possui menor média que o grupo de visionários.

SIQUEIRA, W. R.; PEGHINI, P.; SOUZA, L. D.; OLIVEIRA FILHO, J. B. Atitude empreendedora de proprietários e funcionários intraempreendedores: um estudo comparativo entre visionários e visionistas. Revista de Empreendedorismo e Gestão de Pequenas Empresas, v. 3, n.1, p. 84-104, 2014. 
Tabela 2 - Média e desvio padrão dos dados

\begin{tabular}{|c|c|c|c|c|}
\hline & $\begin{array}{c}\text { GRUPO DE } \\
\text { RESPONDENTES }\end{array}$ & N & MÉDIA & $\begin{array}{c}\text { DESVIO } \\
\text { PADRÃO }\end{array}$ \\
\hline $\begin{array}{c}\text { PROSPECÇÃO } \\
\text { E INOVAÇÃO }\end{array}$ & Visionário & 14 & 150,78 & 22,92 \\
\cline { 2 - 5 } & Visionista & 16 & 147,88 & 18,36 \\
\hline $\begin{array}{c}\text { GESTÃO E } \\
\text { PERSISTÊNCIA }\end{array}$ & Visionário & 14 & 138,00 & 9,38 \\
\cline { 2 - 5 } & Visionista & 16 & 130,68 & 14,01 \\
\hline
\end{tabular}

Fonte: Elaborada pelos autores.

Para comprovar tal resultado estatisticamente, foi realizado o teste de hipótese para comparar estas médias, sendo o resultado apresentado na tabela abaixo.

Tabela 3 - Teste de Hipótese para as médias de amostras independentes

\begin{tabular}{|c|c|c|c|c|c|c|}
\hline & \multicolumn{2}{|c|}{$\begin{array}{l}\text { Teste de Levene } \\
\text { para igualdade de } \\
\text { variâncias }\end{array}$} & \multicolumn{3}{|c|}{$\begin{array}{c}\text { Teste de } t \text { para igualdade } \\
\text { de medias }\end{array}$} \\
\hline & & $F$ & Sig. & $\mathrm{T}$ & DF & $\begin{array}{l}\text { Sig. }(2- \\
\text { tailed })\end{array}$ \\
\hline \multirow{2}{*}{$\begin{array}{l}\text { Dimensão } \\
\text { Prospecção e } \\
\text { Inovação }\end{array}$} & $\begin{array}{l}\text { Assumir } \\
\text { variâncias iguais }\end{array}$ & , 157 & ,695 &,- 386 & 28 & ,702 \\
\hline & $\begin{array}{l}\text { Assumir que as } \\
\text { variâncias não } \\
\text { são iguais }\end{array}$ & & &,- 380 & 24,89 & ,707 \\
\hline \multirow{2}{*}{$\begin{array}{l}\text { Dimensão } \\
\text { Gestão e } \\
\text { Persistência }\end{array}$} & $\begin{array}{l}\text { Assumir } \\
\text { variâncias iguais }\end{array}$ & 2,832 & ,103 & $-1,653$ & 28 & 109 \\
\hline & $\begin{array}{l}\text { Assumir que as } \\
\text { variâncias não } \\
\text { são iguais }\end{array}$ & & & $-1,697$ & 26,33 & ,101 \\
\hline
\end{tabular}

Fonte: Elaborada pelos autores.

A variância encontrada para a dimensão Prospecção e Inovação entre os grupos visionários e visionistas é homogênea considerando o teste de Levene (HAIR JR. et al., 2009), com $\alpha=0,695$ sendo maior que 0,05. Logo, utilizando o teste de t, assumindo que as variâncias são iguais, tem-se que p (Sig. (2-tailed)) > 0,05 (0,702), ou seja, não se pode rejeitar a hipótese nula $\mathrm{H} 1$ de que as médias são iguais. Assim, nesta amostra estudada, a média entre os grupos de visionários e visionistas não 
são diferentes com relação à sua atitude empreendedora dentro da dimensão Prospecção e Inovação.

Na dimensão Gestão e Persistência, o teste de variância feito por Levene (HAIR JR et al., 2009) também revelou que a variância entre os grupos visionários e visionistas é homogênea, com $\alpha=0,103$ sendo maior que 0,05 . Utilizando o teste de t, assumindo que as variâncias são iguais, tem-se que (Sig. (2-tailed)) > 0,05 (0,109), conclui-se também que não se pode rejeitar a hipótese nula $\mathrm{H} 2$ de que as médias são iguais. Da mesma forma, nesta amostra estudada, a média entre os grupos de visionários e visionistas não são diferentes com relação à sua atitude empreendedora dentro da dimensão Gestão e Persistência.

Portanto, os resultados demonstram, especificamente para este estudo, que os visionários e visionistas não diferem quanto à atitude empreendedora dentro das dimensões estudadas. Assim, apesar de numericamente as médias dos visionistas serem menores, estatisticamente elas não apresentam diferenças significativas (ou variação significativa). Concluímos, então, que a diferença encontrada entre as médias das respostas dos visionários e visionistas dentro das duas dimensões propostas na amostra não é estatisticamente significante. Consequentemente, não se pode afirmar que existe diferença de atitude empreendedora, para este estudo em específico, entre os dois tipos: visionários e visionistas, sob a ótica das dimensões.

\section{CONSIDERAÇÕES FINAIS}

Pretendeu-se, com a pesquisa proposta, identificar a atitude empreendedora dos proprietários e dos funcionários intraempreendedores de micro e pequenas empresas do ramo de confecção, especificamente de moda íntima, localizadas no município de Catalão, sudeste de Goiás, frente ao seu negócio. Após identificar a atitude empreendedora foi possível investigar, com base nas características comportamentais empreendedoras e na teoria do comportamento planejado, se existe diferença entre a atitude empreendedora de proprietários (empreendedores visionários) e de funcionários intraempreendedores (visionistas) nesse setor. Os 
resultados obtidos possibilitaram alcançar os objetivos propostos na elaboração deste estudo, por meio da verificação e análise comparativa das dimensões I Prospecção e Inovação e II - Gestão e Persistência.

Os resultados demonstraram não haver diferença de atitude empreendedora, especificamente para este objeto de pesquisa, entre visionários e visionistas dentro das dimensões estudadas. Ambos possuem um papel fundamental no sucesso do negócio. Segundo Filion (2004), enquanto os empreendedores (visionários) tendem a se focalizar em uma ideia central, os intraempreendedores (visionistas) desenvolvem visões emergentes e complementares. O desenvolvimento e a implementação de visões são essenciais tanto para a criação quanto para a sobrevivência do negócio e precisam ser um processo contínuo. A união dessas visões em um empreendimento pode ser um diferencial competitivo, pois ambas possuem capacidade de desenvolver ações que viabilizam o sucesso do negócio.

Neste estudo, o fato de não haver diferença no grau de atitude empreendedora entre os proprietários responsáveis pelo desenvolvimento da visão central e os intraempreendedores coaduna com Pinchot (1989), que apontou a semelhança entre intraempreendedores e empreendedores, diferenciando-os apenas pelo fato de a atuação do primeiro estar voltada para dentro das organizações já estabelecidas. Observa-se que, tanto o proprietário, responsável pela criação do empreendimento, quanto o funcionário intraempreendedor, contratado para atuar no negócio, possuem atitudes empreendedoras, sem que se possa dizer que o primeiro a apresente em maior grau. Essa conclusão está de acordo com o que indica Dornelas (2003, p. 12): "a ideia de se atribuir o empreendedorismo apenas à criação de novos negócios é muito limitada. (...) é possível trazer esse conceito para dentro das organizações estabelecidas e, ainda, fazer com que essas organizações tenham um diferencial com isso".

O desenvolvimento deste estudo apresenta contribuições no avanço de trabalhos e pesquisas sobre empreendedorismo, além de auxiliar empreendedores e potenciais empreendedores quanto às habilidades e conhecimentos necessários à criação e prosperidade de um negócio. Dessa forma, o conhecimento das atitudes empreendedoras de proprietários e funcionários intraempreendedores de micro e

SIQUEIRA, W. R.; PEGHINI, P.; SOUZA, L. D.; OLIVEIRA FILHO, J. B. Atitude empreendedora de proprietários e funcionários intraempreendedores: um estudo comparativo entre visionários e visionistas. Revista de Empreendedorismo e Gestão de

Pequenas Empresas, v. 3, n.1, p. 84-104, 2014. 
pequenas empresas, de maneira detalhada, pode auxiliar os atuais e futuros empresários no desenvolvimento de estratégias para viabilizar a criação ou continuidade de um negócio, aumentando as possibilidades de sucesso.

A pesquisa apresenta como limitações a quantidade de pesquisados, sendo quatorze proprietários (visionistas) e dezesseis funcionários intraempreendedores (visionários), não permitindo, assim, generalizações. É importante ressaltar a necessidade de dar continuidade à pesquisa com outras empresas desse ramo ou não e compará-las. O estudo proporciona bases para aprofundamento do tema, portanto, sugere-se também a utilização de outras técnicas de análise mais estruturadas.

\section{Referências}

ASSOCIAÇÃO BRASILEIRA DE INDÚSTRIA TÊXTIL E DE CONFECÇÃO - ABIT. Setor têxtil fecha semestre com déficit no saldo da balança comercial. Disponível em: <http://www.abit.org.br/content/noticia/noticia.asp?nCodNoticia=2462>. Acesso em: 28 nov. 2011.

AJZEN, I. From intentions to actions: A theory of planned behavior. In: KUHI, J.; BECKMAN, J. (Eds.), Action control: From cognition to behavior. Heidelberg: Springer, p. 11-39, 1985.

The Theory of Planned Behavior. Organizational Behavior and Human decision Processes, v. 50, p. 179-211, 1991.

AJZEN, I; FISHBEIN, M. Attitudes and Attitude-Behavior Relation: reasoned and automatic processes. In: STROBE, W.; HEWSTONE, M. (Ed.), European Review of Social Psychology, p. 1-33, John Wiley and Sons, 2000.

BARON, R. A.; SHANE. S. A. Empreendedorismo: uma visão do processo. São Paulo: Thomson Learning, 2007.

BERNARDES, M. E. B.; MARTINELLI, D. P. Programa de Empreendedorismo em Instituições de Ensino Superior: reflexões a partir de algumas experiências canadenses e americanas. In: III EGEPE - Encontro de Estudos sobre Empreendedorismo e Gestão de Pequenas Empresas, 11, Brasília, Anais ... Brasília, p.1-13, 2003,

CARRIERI, A. de P.; LUZ, T. R. da. Paradigmas e Metodologias: não existe pecado do lado de baixo do equador. In: ENANPAD, Foz do Iguaçu, PR, 1998.

SIQUEIRA, W. R.; PEGHINI, P.; SOUZA, L. D.; OLIVEIRA FILHO, J. B. Atitude empreendedora de proprietários e funcionários intraempreendedores: um estudo comparativo entre visionários e visionistas. Revista de Empreendedorismo e Gestão de

Pequenas Empresas, v. 3, n.1, p. 84-104, 2014. 
DEGEN, R. J. O Empreendedor: empreender como opção de carreira. São Paulo: Person Prentice Hall, 2009.

DORNELAS, J. C. A. Empreendedorismo corporativo: Como ser empreendedor, inovar e se diferenciar na sua empresa. Rio de Janeiro: Campus, 2003.

FILION, L. J. O planejamento do seu sistema de aprendizagem empresarial: identifique uma visão e avalie o seu sistema de relações. Revista de Administração de Empresas - RAE, São Paulo, v. 31, n. 3, p. 63-72, jul/set 1991.

. Empreendedorismo: empreendedores e proprietários-gerentes de pequenos negócios. Revista de Administração, São Paulo, v. 34, n. 2, p. 05-28, abr/jun 1999.

. Aprender a Empreender. In: FILION, L. J; DOLABELA, F. (Org.). Boa Idéia! E agora? plano de negócio, o caminho seguro para criar e gerenciar sua empresa. São Paulo: Cultura, p. 226-241, 2000a..

Empreendedorismo e gerenciamento: processos distintos, porém complementares. Rev. adm. empres. [online]. v. 40, n. 3, p. 8-17, 2000 b.

. Entendendo os Intraempreendedores como Visionistas. Revista de Negócios, Blumenau, v. 9, n. 2, p. 65-80, abr/jun 2004.

HAIR JR., J. F. et al. Análise Multivariada de Dados. 6 ed. Bookman: Porto Alegre, 2009.

HORA, H. R. M. da; MONTEIRO, G. T. R.; ARICA, J. Confiabilidade em Questionários para Qualidade: Um Estudo com o Coeficiente Alfa de Cronbach, Produto \& Produção, v. 11, n. 2, p. 85-103, jun. 2010.

IEDI. Instituto de Estudos para o Desenvolvimento Industrial. Trabalho preparado por Carlos Américo Pacheco. Uma comparação entre a agenda de inovação da China e do Brasil, São Paulo: IEDI, 2011.

LOPEZ JR., G. S; SOUZA, E. C. L. de. Atitude empreendedora em proprietáriosgerentes de pequenas Empresas: Construção de um instrumento de medida. Revista Eletrônica de Administração - REAd, Porto Alegre, v. 11, n. 6, nov/dez 2005.

MANAGEMENT SYSTEMS INTERNATIONAL. Treinamento empresarial e fortalecimento do desempenho empresarial. Relatório Final de Pesquisa. Boston: MSI, n. 1, out. 1999.

MARCONI, M. de A.; LAKATOS, E. M. Técnicas de pesquisa: planejamento e execução de pesquisas, amostragens e técnicas de pesquisa, elaboração, análise e interpretação de dados. 6 ed., São Paulo: Atlas, 2006.

SIQUEIRA, W. R.; PEGHINI, P.; SOUZA, L. D.; OLIVEIRA FILHO, J. B. Atitude empreendedora de proprietários e funcionários intraempreendedores: um estudo comparativo entre visionários e visionistas. Revista de Empreendedorismo e Gestão de

Pequenas Empresas, v. 3, n.1, p. 84-104, 2014. 
PINCHOT, G. Intrapreneuring: por que você não precisa deixar a empresa para tornar-se um empreendedor. In: . Tradução Nivaldo Montingelli Jr. São Paulo: Harbra, 1989.

SOUZA, E. C. L. Empreendedorismo: da gênese à contemporaneidade. In: SOUZA, E. C. L.; GUIMARÃES, T. de A. (Org.). Empreendedorismo além do plano de negócio. São Paulo: Atlas, 2006, p. 3-20.

Artigo recebido em: 07/08/2013. Artigo aprovado em: 17/04/2014

SIQUEIRA, W. R.; PEGHINI, P.; SOUZA, L. D.; OLIVEIRA FILHO, J. B. Atitude empreendedora de proprietários e funcionários intraempreendedores: um estudo comparativo entre visionários e visionistas. Revista de Empreendedorismo e Gestão de 